\title{
23. COLOR-REFLECTANCE MEASUREMENTS OBTAINED FROM LEG 155 CORES ${ }^{1}$
}

\author{
R.R. Schneider, ${ }^{2}$ A. Cramp, ${ }^{3}$ J.E. Damuth ${ }^{4}$ R.N. Hiscott, ${ }^{5}$ R.O. Kowsmann, ${ }^{6}$ M. Lopez, ${ }^{7}$ F. Nanayama, ${ }^{8}$ \\ W.R. Normark, ${ }^{9}$ and Shipboard Scientific Party ${ }^{10}$
}

\section{INTRODUCTION}

During ODP Leg 155 , color reflectance was routinely measured downhole at all but one site to determine light-reflectance levels in the wavelength band of visible light ( 400 to $700 \mathrm{~nm}$ ) of the sediments recovered. Reflectance measurements taken on previous ODP legs have demonstrated that lithologic changes in carbonate-rich $(>20 \%)$ pelagic and hemipelagic sediments can be characterized using these data (e.g., Mix et al., 1992: ODP Leg 138; Curry, Shackleton, Richter, et al., in press: ODP Leg 154). This chapter briefly summarizes our attempts to apply this method to deep-sea fan sediments, which, in general, are characterized by low carbonate and are predominantly terrigenous siliciclastic material. Problems determining color reflectance of terrigenous sediments typical for the Amazon Fan by using a hand scanner system involve both technique and non-mineral characters of the sediment. The method for measurement of color reflectance is described in the "Explanatory Notes" chapter (this volume), and detailed comparisons between color-reflectance patterns and lithology of sediments at individual sites are given in the "Lithostratigraphy" sections of each site report (this volume).

\section{GENERAL RESULTS AND PROBLEMS \\ Reflectance of Individual Wavelengths}

The dark-colored terrigenous clays, muds, and sands drilled during Leg 155 generally show low reflectance of visible light. Reflectance levels of these terrigenous sediments never exceeded $28 \%$ in the wavelength band between 400 and $700 \mathrm{~nm}$ (Fig. 1). Only the thin Holocene calcareous clays recovered at the top of all holes produced reflectance values as high as $35 \%$. In contrast, the 550 -nm reflectance levels of late Quaternary sediments from the Ceara Rise just northeast of the Amazon Fan fluctuate between $10 \%$ and $60 \%$, and correspond to variations in the high carbonate content (20\% and $80 \%)$ (T. Bickert, pers. comm., 1994).

The downhole reflectance records of the dark colors of the Amazon Fan sediments (see Munsell color codes in core descriptions at

'Flood, R.D., Piper, D.J.W., Klaus, A., et al., 1995. Proc. ODP, Init. Repts., 155: College Station, TX (Ocean Drilling Program).

${ }^{2}$ Fachbereich Geowissenschaften, Universität Bremen, Postfach 330440, D-28334 Bremen, Federal Republic of Germany.

'Department of Geology, University of Wales, College of Cardiff, P.O. Box 914, Cardiff CF13YE, United Kingdom.

${ }^{4}$ Department of Geology, University of Texas at Arlington, P.O. Box 19049, Arlington, TX 76019, U.S.A.

${ }^{5}$ Department of Earth Sciences, Centre for Earth Resources Research, Memorial University, St. John's, Newfoundland A1B 3X5, Canada.

${ }^{6}$ Petrobras/Cenpes/Divex, Cidade Universitária Q.7, Itha Do Fundaõ, Rio de Janeiro CEP 21949-900, Brazil.

'Laboratoire de Dynamique Sédimentaire et Structurale, SN.5, Université de Lille I, 59655 Villeneuve D'Ascq Cedex, France.

${ }^{8}$ Department of Earth and Planetary Sciences, Kyushu University, 6-10-1 Hakozaki, Higashi-ku, Fukuoka 812, Japan.

${ }^{9}$ U.S. Geological Survey, 345 Middlefield Road, Menlo Park, CA 94025, U.S.A.

${ }^{10}$ Shipboard Scientific Party is as given in the list of participants in the contents. end of volume) are dominated by high-frequency variability that results either from instrument deviations or from sediment conditions. White reference readings, taken as a standard before each core was measured, show an analytical background variability corresponding to $10 \%$ to $20 \%$ of total variability associated with the terrigenous sediments (Fig. 1). Most of these analytical fluctuations probably result from the plastic wrap that was placed between the scanner and the white cap to keep the reference readings comparable to core measurements (the plastic wrap was required to protect the scanner lens from

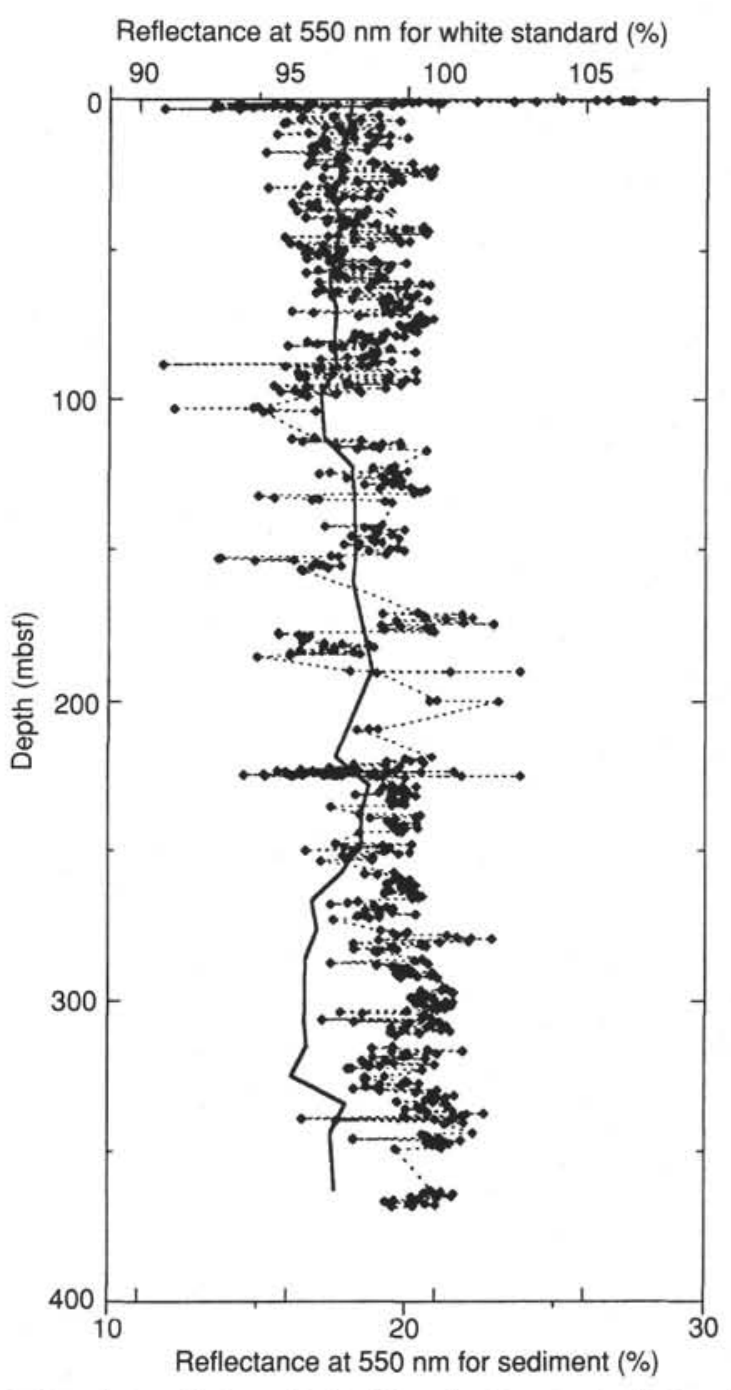

Figure 1. Downhole reflectance for the $10-\mathrm{nm}$ band centered at $550 \mathrm{~nm}$ from Hole 935A (dashed line with data points). For comparison, reflectance from the white calibration cap is shown for the same wavelength (solid line). 


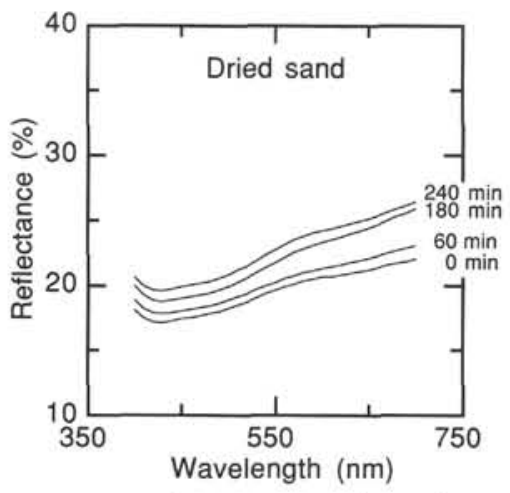

Figure 2. Reflectance spectra for a representative sand sample that was airdried under shipboard lab conditions and measured at intervals of $60 \mathrm{~min}$. Each line represents an average of 12 to 15 individual measurements taken at the respective time intervals.

the wet and abrasive sediment). Further complications arise from changing laboratory conditions such as temperature, humidity, and background light. Sedimentary features that caused high-frequency reflectance variability were the occurrence of millimeter-scale silt or sand laminae, often separated by gas partings (e.g., Fig. 8 of "Site 930" chapter, this volume) and the presence of black color banding or mottling associated with hydrotroilite, which is commonly disseminated in the fan sediments (see Fig. 7 of "Site 935" chapter, and "Introduction" chapter, this volume). As a consequence, it was impossible to correlate the reflectance pattern of individual wavelengths to distinctive lithologies.

\section{Effects of Dewatering and Reoxygenation}

In addition to problems originating from the scanning system and core conditions affecting reflectance readings, the possibility of two other effects was investigated during shipboard measurements. One is the differential drying of sediment, either because of time-consuming lab operations and core storage prior to measurement, or as a result of random dewatering, particularly in sand-rich sediment, which occurs during core splitting. The effect of successive drying of sand layers is shown in Figure 2. Drying increases the reflectance levels of sands at all measured wavelengths by only a small percentage. In the case of Amazon Fan sediments, however, where color differences are subtle, this effect can contribute significantly to the high-frequency variability observed in all downhole reflectance records from Leg 155 sites. The slightly higher rate of reflectance increase in the red spectrum (650-700 nm; Fig. 2) can be attributed to traces of reduced iron that, under exposure of the sediment to the atmosphere, were oxidized and turned more brownish in color. This reoxygenation of primary anoxic sediments raises another problem associated with the reflectance measurements of terrigenous organic- and iron-rich sediment. Several hours of exposure to atmospheric oxygen produced an increase in overall reflectance, but did not change the relative reflectance levels between individual wavelengths (Fig. 3). This suggests that drying of the sediment is the major factor for the change in reflectance levels within a few hours after splitting the cores. After several days, the sediment substantially changed in color from black or dark greenish gray to brownish gray, even though they were stored in sealed liner boxes at a temperature of about $4^{\circ} \mathrm{C}$. Thus, reflectance measurements obtained on board cannot be reproduced later for comparison with more detailed shore-based studies because of the substantial color change the sediment has undergone in response to reoxygenation of reduced iron phases. This diagenetic overprint destroys the original pattern of reflectance (color) changes, and, thus, weakens the potential for routine reflectance measurements made on

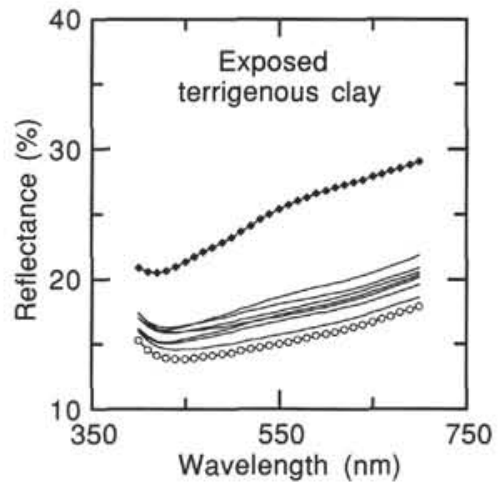

Figure 3. Spectra of reflectance measurements taken from a terrigenous clay in Core 155-941B-2H containing very high amounts of iron sulfides (hydrotroilite). Each line represents an average of 12 to 15 individual measurements, randomly taken in Section 3, 20-70 cm. Line with open circles = reflectance measured on the fresh sediment $15 \mathrm{~min}$ after core splitting; single lines $=$ measurements taken at intervals of $60 \mathrm{~min}$; line with solid diamonds $=$ reflectance of the terrigenous clay after 3 days storage in a sealed liner box at about $4^{\circ} \mathrm{C}$.

wet sediments as a tool for inter-core correlations, as well as more quantitative color-based characterization of Amazon Fan sediments. Color scanner readings and the color core photographs are thus the only records that exist of the original sediment colors commonly used for shipboard correlation of sediment facies.

Note that all reflectance spectra in Figures 2 and 3 exhibit inflections to higher values in the $400-\mathrm{nm}$ increment. This increase results from the use of the plastic wrap, and, therefore, wavelengths below $450 \mathrm{~nm}$ should not be utilized.

\section{Ratio of Red and Blue Spectrum Reflectance}

As described above, a major part of downhole variability observed in the reflectance records at specific wavelengths must be attributed to processes independent of changes in the primary color of the distinctive lithologies recovered. For reflectance measurements of Amazon Fan sediments, the ratio of the red vs. blue spectrum reflectance $(650-700 \mathrm{~nm} / 450-500 \mathrm{~nm})$ is a more diagnostic indicator of lithologic changes than is the reflectance of individual wave bands. Similar to other studies on color reflectance (Barranco et al., 1989; Mix et al., 1992), measurements of Amazon Fan sediment indicate that traces of reduced or oxidized phases of iron can significantly change the reflectance pattern in the spectrum from 400 to $700 \mathrm{~nm}$. Iron oxyhydroxides are highly reflective in the red $(650-700 \mathrm{~nm})$ band, whereas diagenetic sulfide minerals often have reflectance maxima in the lower (450-500 nm) visible bands (Mix et al., 1992). For Amazon Fan sediment, four different end members of typical reflectance pattern can be isolated based on carbonate content and traces of reduced or oxidized iron phases (Fig. 4).

The Holocene carbonate-rich sediments containing high amounts of iron oxyhydroxides are marked by elevated reflectance levels $(25 \%)$ and highest reflectance is in the red spectrum (35\%; Fig. 4A) and a red/blue ratio of about 1.6. Relatively high overall reflectance was also measured on Pleistocene calcareous clay intervals recovered in deeper cores. In these cases, resulting from the occurrence of iron sulfides instead of oxyhydroxides, reflectance in the red spectrum is as low as in the blue spectrum (Fig. 4B). Thus, calcareous clays from deeper cores have red/blue ratios near 1 . The sediment containing exclusively terrigenous detritus is characterized by very low overall reflectance ( $12 \%$ to $20 \%$ ) and cannot be distinguished by differences in the reflectance of individual wavelengths. Only the fact that quartz grains are stained with red iron coatings allows the differentiation of 


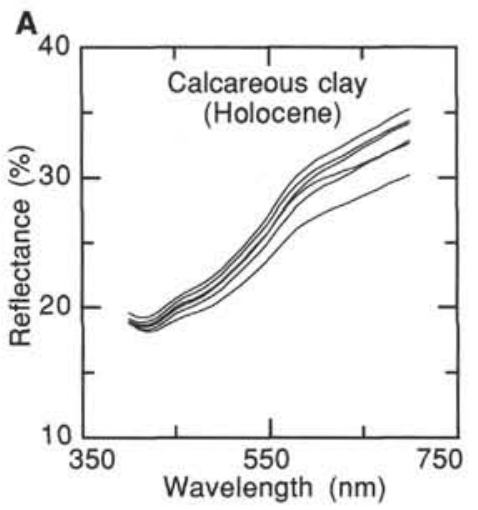

B

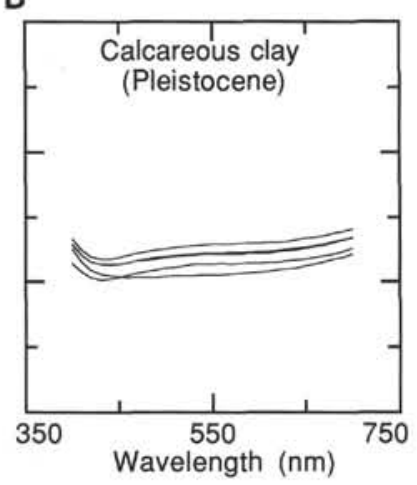

C

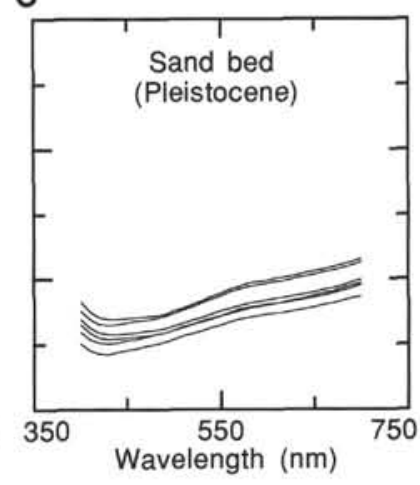

D

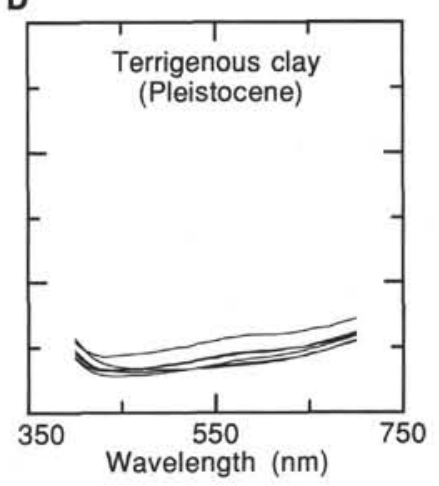

Figure 4. Examples of complete reflectance spectra $(400$ to $700 \mathrm{~nm})$ characteristic of distinctive lithologies recovered from Hole $935 \mathrm{~A}$. A. Holocene calcareous clay representative of lithologic Unit I at all sites. B. Interglacial calcareous clay from $280 \mathrm{mbsf}$. C. Pleistocene sand bed, several meters thick, recovered at 100 mbsf. D. Terrigenous silty clay or mud without silt or sand laminae and beds, but containing high amounts of iron monosulfide at about 3 mbsf.

sand-rich sediment sequences from terrigenous clay or mud. Compared to the terrigenous fine fraction, sand beds have slightly enhanced red reflectance and thus slightly higher red/blue ratios (Fig. $4 C$, -D). Thus, changes in the red/blue ratio within terrigenous sediment units can indicate relative changes in the coarse-grained component.

Downhole variations in the ratio of red/blue-spectrum reflectance generally are related to lithologic changes (see "Spectrophotometry" in "Lithostratigraphy" sections of individual site chapters, this volume). The approximately parallel single lines, each representing one reflectance reading of the whole 400- to 700-nm spectrum (Figs. 2, 3, 4A-D), suggest that the effect of millimeter-scale laminae, gas partings, diagenetic imprints (color banding and mottling), and partial differences in sediment wetness on reflectance measurements are nearly the same within the entire spectrum of visible light. Thus, considering the ratio of red-and blue-spectrum reflectance reduces the high-frequency variability that results from secondary changes in core conditions and millimeter-scale variations in lithology. Further, the variability induced from instrument handling, which is reflected by variability in the white-reflectance readings (see above), diminishes significantly as observed in the record of red/blue ratios taken before each core of Hole 935B was measured (Fig. 5). As predicted from the results presented in Figure 4, the uppermost decimeters of sediment that contain the Holocene calcareous clay reveal red/blue ratios up to 1.6, whereas deeper calcareous clay at 225 and $270 \mathrm{mbsf}$ have ratios of about 1.05 (Fig. 5; see also Fig. 9 of "Site 935" chapter, this volume). The red/blue ratios of most of the terrigenous sediment fluctuate between 1.10 and 1.20 , whereby sand-rich layers (e.g., at 130 and $182 \mathrm{mbsf}$ ) or the downward-coarsening sequences at about 100 and $340 \mathrm{~m}$ reach ratios greater than 1.2.

\section{Summary}

The Leg 155 color-reflectance measurements yielded new information about the application of a hand-held scanning system to hemipelagic and terrigenous continental-margin sediments that are characterized by high amounts of biogenic gas, organic carbon (about $1 \%$ dry wt), and reduced or oxidized phases of iron:

1. Pronounced differences in reflectance levels within the spectrum of visible light primarily correlate only with significant changes in carbonate content that generally are restricted to a few thin stratigraphic intervals (e.g., Holocene and some interglacials) in the recovered Amazon Fan sediments.

2. Problems arise with the manual use of the scanner, with millimeter-scale changes in lithology, and with diagenetic over-

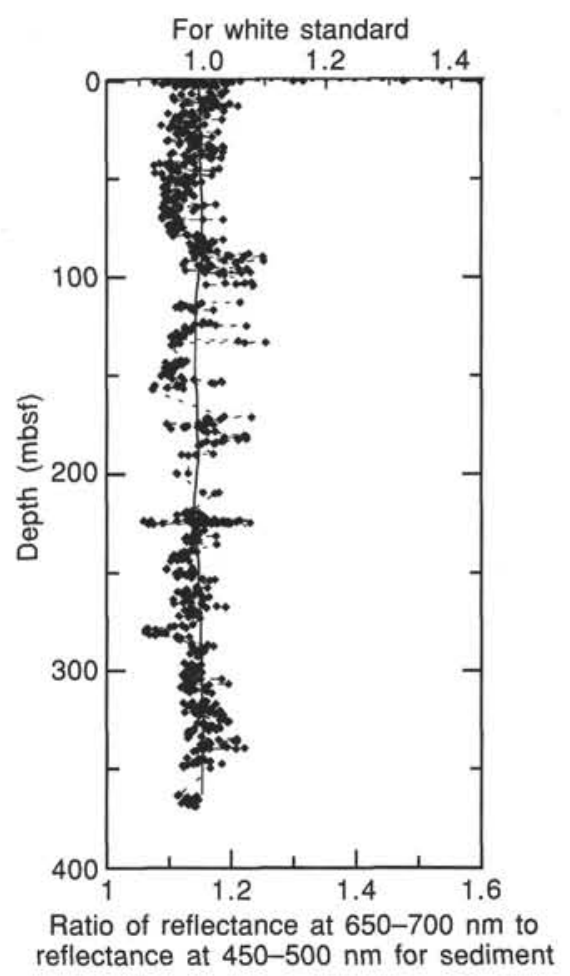

Figure 5. Downhole ratio of the red- $(650-700 \mathrm{~nm})$ and the blue-spectrum $(450-500 \mathrm{~nm}$ ) reflectance for sediment recovered in Hole 935A (dashed line with data points) compared with red/blue ratios of white-reflectance reference readings (solid line).

prints on color, as well as with gas partings. These conditions led to high-frequency variability masking reflectance changes associated with major changes in mineral composition of the terrigenous sediment. The use of plastic wrap to cover the wet sediment as well as changing lab conditions produce artificial noise both in instrument calibrations and in the core measurements. This noise can dominate the downhole reflectance record because color changes within the major lithologies are subtle.

3. The most valuable indicator for lithologic changes in the thick terrigenous sediment wedges composing the channel-levee 
systems of the fan is the ratio between reflectance of the red and the blue spectrum. This ratio is controlled by traces of iron, which (particularly in the Amazon Fan sediments) occur in distinctive lithologic units either as reduced or oxidized mineral phases and coatings. The use of the red/blue ratio of light reflectance as a tool for sediment classification in postcruise studies is restricted because of the reoxygenation of reduced iron phases, which changes sediment colors substantially during lab work and storage.

\section{ACKNOWLEDGMENTS}

The first author thanks the Ocean Drilling Program for invitation to Leg 155 and the German Science Foundation for financial support. The Leg 155 lithology team acknowledges very much the assistance and the (sometimes humorous) comments on spectroscopy results rendered on board the JOIDES Resolution from our shipmates.

\section{REFERENCES*}

Barranco, F.T., Jr., Balsam, W.L., and Deaton, B.C., 1989. Quantitative reassessment of brick red lutites: evidence from reflectance spectrophotometry. Mar. Geol., 89:299-314.

Curry, W.B., Shackleton, N.J., Richter, C., et al., in press. Proc. ODP, Init. Repts., 154: College Station, TX (Ocean Drilling Program).

Mix, A.C., Rugh, W., Pisias, N.G., Veirs, S., Leg 138 Shipboard Sedimentologists (Hagelberg, T., Hovan, S., Kemp, A., Leinen, M., Levitan, M., Ravelo, C.), and Leg 138 Scientific Party, 1992. Color reflectance spectroscopy: a tool for rapid characterization of deep-sea sediments. In Mayer, L., Pisias, N., Janecek, T., et al., Proc. ODP, Init. Repts., 138 (Pt. 1): College Station, TX (Ocean Drilling Program), 67-77.

*Abbreviations for names of organizations and publications in ODP reference lists follow the style given in Chemical Abstracts Service Source Index (published by American Chemical Society).

Ms 155IR-123 